\title{
Root-Associated Microbiome of Maize Genotypes with Contrasting Phosphorus Use Efficiency
}

Eliane A. Gomes, ${ }^{\dagger}$ Embrapa Maize and Sorghum, Sete Lagoas, MG 35701-970, Brazil, and Center for Microbial Ecology, Department of Plant, Soil and Microbial Sciences, Michigan State University, East Lansing 48824; Ubiraci G. P. Lana, Embrapa Maize and Sorghum, Sete Lagoas, MG 35701-970, Brazil; John F. Quensen, Center for Microbial Ecology, Department of Plant, Soil and Microbial Sciences, Michigan State University, East Lansing 48824; Sylvia M. de Sousa and Christiane A. Oliveira, Embrapa Maize and Sorghum, Sete Lagoas, MG 35701970, Brazil; Jiarong Guo, Center for Microbial Ecology, Department of Plant, Soil and Microbial Sciences, Michigan State University, East Lansing 48824; Lauro J. M. Guimarães, Embrapa Maize and Sorghum, Sete Lagoas, MG 35701-970, Brazil; and James M. Tiedje, Center for Microbial Ecology, Department of Plant, Soil and Microbial Sciences, Michigan State University, East Lansing 48824

Accepted for publication 16 August 2018.

\section{ABSTRACT}

Marginal soil fertility, soil acidity, aluminum toxicity, and a generalized low level of available nutrients, especially phosphorus $(P)$, are major limiting factors to maize production in highly weathered oxisols that are prominent in the tropics. Plants have evolved several strategies to improve $P$ acquisition, including the ability to associate with soil microorganisms that potentially enhance $P$ uptake and plant nutrition. We investigated the effect of two maize genotypes with contrasting $P$ use efficiency and their hybrid, grown in soils with two $P$ levels, on bacterial and fungal community structures in the root and the rhizosphere. We found that a significant fraction of bacterial and fungal diversity could be attributed to the host genotype, but in general, the soil $\mathrm{P}$ level was the major driver of microbiome structure followed by plant compartment (rhizosphere versus directly root associated).
Slow-growing bacterial taxa increased in the low $\mathrm{P}$ soil, whereas fast-growing taxa were enriched in high $P$ soil. The low $P$ soil had a positive effect on arbuscular mycorrhizal fungi abundance, as expected, particularly inside the root. On the other hand, our results did not support selection for microbes associated to plant growth promoting and $\mathrm{P}$ solubilization based on $\mathrm{P}$ availability. Taken together, our results expand knowledge of which microbial groups are favored in P-deficient oxisol and suggest that $\mathrm{P}$ fertilization significantly impacts the species composition and diversity indices of bacteria and fungi communities, both inside the roots and in the rhizosphere.

Additional keywords: maize, plant-microbe interactions, Zea mays.
Phosphorus (P) is usually the most limiting nutrient to crops in oxisols, well known in the extensive acid Savanna (Cerrado) areas in Brazil, resulting in its low P use efficiency by plants, which can be less than 10\% (Fageria 2009). These low efficiencies are due to significant losses by $\mathrm{P}$ fixation, forming insoluble complexes with

${ }^{\dagger}$ Corresponding author: E. A. Gomes; E-mail: eliane.a.gomes@embrapa.br

Funding: Funding was provided by Empresa Brasileira de Pesquisa Agropecuária, Fundação de Amparo à Pesquisa do Estado de Minas Gerais (FAPEMIG), CNPq, the Embrapa Macroprogram, Conselho Nacional de Desenvolvimento Científico e Tecnológico, and partial funding by the US DOE Office of Science BER DE (FC02-07ER64494)

*The $\boldsymbol{e}$-Xtra logo stands for "electronic extra" and indicates that one supplementary file and five supplementary tables are published online.

(c) 2018 The American Phytopathological Society the constituents of soil and/or $\mathrm{P}$ precipitation by free $\mathrm{Al}^{3+}$ and $\mathrm{Fe}^{3+}$. Therefore, to obtain high yields of most crops, which is particularly true of maize, additions of chemical fertilizers are required, which significantly increase the cost of production (Novais and Smyth 1999).

This scenario indicates that $\mathrm{P}$-efficient maize genotypes are key to a sustainable and competitive agricultural production system. P use efficiency in maize is composed of acquisition and internal utilization but on Brazilian oxisols, $\mathrm{P}$ acquisition efficiency is more relevant (Parentoni et al. 2010). The main features related to $P$ acquisition efficiency include changes in root morphology and architecture (de Sousa et al. 2012), secretion of organic compounds in the rhizosphere (Lynch 2011), and the genotype's ability to associate with beneficial microorganisms (Sharma et al. 2013).

Microorganisms can increase $\mathrm{P}$ acquisition of plants either by facilitating the transport of this nutrient to the roots via mycorrhizal 
fungi (Smith and Read 2008) or by solubilization or mineralization of sparingly available sources of inorganic and organic P (Mander et al. 2012). Microorganisms can benefit plant growth by several other mechanisms, such as nitrogen fixation, production of ammonia, siderophores and phytohormones (Sharma et al. 2013). Maize roots passively exude organic compounds such as sugars, organic acids, nucleosides, mucilage, and amino acids, producing concentration gradients that can attract microorganisms from the bulk soil to the rhizosphere and to the endosphere (Edwards et al. 2015) as well as accelerate their growth. Root exudates vary according to plant genotype, root type and hence modify the structure of rhizosphere microbial communities. It has been shown that hybrids have an advantage over less vigorous homozygous inbred line seedlings (Hoecker et al. 2006; Paschold et al. 2010) and that this heterosis can indirectly alter root morphology and physiology (Matsuo and Hoshikawa 1993). Therefore, heterosis might also induce significant differences in the frequency and biodiversity of rhizospheric microbial populations associated with hybrid genotypes, due to the different composition of their root exudates. For example, a study showed that maize hybrids are able to select specific bacterial strains, increasing the diversity of rhizosphere bacteria whereas their parents did not (Picard and Bosco 2005; Picard et al. 2008).

Our previous isolation of P-solubilizing bacteria (PSB) of the genera Bacillus, Burkholderia and Streptomyces and high arbuscular mycorrhizal fungi (AMF) root colonization in P-efficient maize genotypes under P stress (Oliveira et al. 2009a, b) suggested that maize genotypes could influence the microbial communities present in their rhizosphere and roots. While plant genotype driven beneficial microbiomes remains a worthy goal, factors such as soil properties, fertilizers, plant developmental stages, nutritional status of the host plant, and other environmental factors can have greater or confounding effects on microbial communities (Bakker et al. 2015; Li et al. 2014; Mota et al. 2008).

Based on the above, we hypothesized that not only do the efficient maize genotypes recruit microorganisms that enhance $\mathrm{P}$ uptake but also that the soil P status alters AMF and PSB community structure. Therefore, we used MiSeq amplicon sequencing to determine (i) if $\mathrm{P}$ soil fertilization affects the structure of microbial communities; (ii) the extent to which the presence of a Pefficient plant genotype shapes bacterial and fungi communities in the maize roots system; and (iii) if $\mathrm{P}$ availability drives the selection of AMF and PSB in the root system of maize. These results can have implications for inoculant development and might help identify strategies to improve the benefits of these microorganisms applicable to sustainable agricultural systems, especially in P-deficient soils.

\section{MATERIALS AND METHODS}

Field description and sampling. We evaluated two maize lines, L3 (P-efficient) and L22 (P-inefficient), and an F1 cross between them (L3xL22 hybrid) from Embrapa breeding program for phosphorus efficiency in tropical maize (Parentoni et al. 2010) in a randomized complete block design with four replications in each environment at the Embrapa Maize and Sorghum Research Center, in Brazil (latitude $19^{\circ} 27^{\prime} \mathrm{S}$ and $716 \mathrm{~m}$ ). Each experimental plot consisted of two rows, $3 \mathrm{~m}$ long, with $0.8 \mathrm{~m}$ between rows and $0.2 \mathrm{~m}$ between plants. The trial was conducted during the summer season on a clay dark red Oxisol soils, previously characterized as savanna vegetation (i.e., Cerrado), in two environments with contrasting $\mathrm{P}$ levels evaluated using the Mehlich 1 extractor. Low and high $\mathrm{P}$ area had 4.4 and $15.3 \mathrm{mg} \mathrm{dm}^{3}$ of $\mathrm{P}$, respectively, in the 0 to $20 \mathrm{~cm}$ layer. In both areas, a mixture of $20 \mathrm{~kg} \mathrm{ha}^{-1}$ of $\mathrm{N}$ and $60 \mathrm{~kg} \mathrm{ha}^{-1}$ of $\mathrm{K}_{2} \mathrm{O}$ were applied at planting. In addition, the high $\mathrm{P}$ area also received $200 \mathrm{~kg} \mathrm{ha}^{-1}$ of triple superphosphate at planting corresponding to $90 \mathrm{~kg} \mathrm{ha}^{-1}$ of $\mathrm{P}_{2} \mathrm{O}_{5}$ or $39.3 \mathrm{~kg} \mathrm{ha}^{-1}$ of $\mathrm{P}$. The low $\mathrm{P}$ area did not receive additional $\mathrm{P}$. Thirty days after planting, $90 \mathrm{~kg} \mathrm{ha}^{-1}$ of $\mathrm{N}$ was applied as urea and both areas received the same nutrient and agronomic management. The local climate is the $\mathrm{Aw}$, according to the Köppen classification, with the mean temperature $22^{\circ} \mathrm{C}$, rainfall $1,300 \mathrm{~mm}$, and a mean relative humidity of $70 \%$. Irrigation was provided at all sites as needed in order to avoid drought stress. Weed management was done manually.

Each biological replicate for the sequencing analysis came from roots of five randomly chosen plants collected 60 days after planting, during flowering stage. In the lab, $5 \mathrm{~g}$ (fresh weight) of the fine roots with adhering rhizosphere soil from each replicate were cut separately, shaken over a sieve to remove and discard any loose soil and washed in a solution of $0.1 \%$ (wt/vol) sodium pyrophosphate for $60 \mathrm{~min}$ on a horizontal shaker. Surface washed roots were separated and the wash solutions containing the rhizosphere soil were centrifuged at $6,000 \times g$ for $15 \mathrm{~min}$ at $4^{\circ} \mathrm{C}$, and stored at $-80^{\circ} \mathrm{C}$ until DNA extraction. In total, 48 samples were evaluated: three plant genotypes, two levels of soil $\mathrm{P}$, four replicates and rhizosphere and root associated microorganisms (rhizoplane and endosphere, hereafter termed root).

DNA extraction and Illumina MiSeq sequencing. Roots including endophytes and outer surface-bound microorganisms were macerated in liquid nitrogen and DNA was extracted using the DNeasy Plant kit (Qiagen, Germany). For rhizospheric soil samples, the extraction was carried out using the PowerSoil DNA Isolation kit (MoBio Laboratories, Inc., CA), according manufacturer's instructions. All DNA templates were quantified using a Qubit 2.0 Fluorometer (Life Technologies, Grand Island, NY) and diluted to concentrations of $10 \mathrm{ng} \mu \mathrm{l}^{-1}$. For bacteria, a 291-bp 16S rRNA gene fragment capturing the hypervariable V4 region was amplified using the primers 515F and 805R (Caporaso et al. 2011). For fungi, the ITS2 region of variable length (from 150 to $400 \mathrm{bp}$ ) was PCR-amplified using the primers ITS9F (Egger 1995) and ITS4R (White et al. 1991). The samples were sequenced at the DOE-JGI (Department of Energy, Joint Genome Institute, CA) using Illumina MiSeq technology with a $2 \times 250$ bp reads configuration using Illumina's v2 chemistry. Before sequencing, PhiX spike-in shotgun library reads were added to the amplicon pools for a final concentration of about 20 to $25 \%$ of the $\sim 12 \mathrm{M}$ pairedends reads library. Each sample was amplified in triplicate, pooled and then sequenced on a single lane of MiSeq Illumina in 96-well plate format, according to the JGI guidelines. All general aspects of iTAG sequencing performed can be found at http://jgi.doe.gov/ user-program-info/pmo-overview/.

Sequence analysis. Initial processing was performed by JGI. Briefly, reads were first scanned for contaminants (e.g., Illumina adapter sequences) and PhiX spike-in reads were removed (Tremblay et al. 2015). For sequence quality control, EA-Utils (Aronesty 2013) was used for trimming low quality bases, FLASH (Magoč and Salzberg 2011) for joining pair ends, and Cutadapt (Martin 2011) to remove primers from the sequences.

For community analysis, subsampled open reference OTU picking method in QIIME (Caporaso et al. 2010) was used for clustering, and the RDP Classifier and UCLUST implemented in QIIME were used for taxonomic classification of 16S rRNA and ITS gene fragments, respectively. A SILVA version 108 SSU rRNA gene reference set provided by QIIME was used as classification database for $16 \mathrm{~S}$ rRNA gene fragments and OTUs classified as Eukaryota, chloroplast (plastids), and mitochondria by QIIME were filtered out. A UNITE ITS reference set provided by QIIME (version 12_11) was used as classification database for 
ITS gene fragments. Nucleotide sequences were deposited in the European Nucleotide Archive (https://www.ebi.ac.uk/ena) as study PRJEB24131 under accession numbers ERR2233351 through ERR2233446.

Data analysis. OTU and classification tables and sample data (treatment assignments) were combined into biom files and imported into phyloseq objects (McMurdie and Holmes 2013) for analyses. For the 16S rRNA data, representative sequences for each OTU were treed using FastTree and the tree included in the phyloseq object. For the ITS data, the classification table was modified by subdividing the Gigasporaceae to include also the Scutellosporaceae and Racocetraceae according to Oehl et al. (2008).

Chao1, Shannon, and Pielou's $J$ indices (measures of $\alpha$-diversity) were used to assess community richness, diversity and evenness, respectively. Data were sampled without replacement to have the same number of counts per sample: 14,472 for bacteria and 3,456 for fungi using the rarefy function in the R package vegan (Oksanen et al. 2017). Prior to testing for differences between means, the Fligner-Killeen test was used to test for heterogeneity of variances. If heterogeneity was indicated ( $\alpha \leq 0.1$ ), vegan's one-way test based on Welch's method allowing for unequal variances was used, and if results were significant, the pairwise.t.test function with unequal variances and Benjamini and Hochberg adjusted $P$ values was used to make multiple comparisons among groups. If heterogeneity of variances was not indicated, the Chao 1 and Pielou's $J$ indices were analyzed by two-way analysis of variance (ANOVA) with P level and genotype as the factors. If interaction was significant, pairwise comparisons were made by pairwise $t$ tests with equal variances. Differences were declared significant at $\alpha=0.05$.

Differences in community structure among samples ( $\beta$-diversity) were assessed by principal coordinate analysis (PCoA) based on generalized UniFrac distances calculated with $\alpha$ parameter set to 0.5 for the 16S rRNA gene data and on Bray-Curtis distances calculated from log transformed counts (as implemented by vegan's decostand function) for the ITS data. The betadisper function in vegan was used to compare group dispersions and the adonis function, an implementation of Anderson's (2001) permutational multivariate analysis of variance (PERMANOVA) test, was used to test for significant differences among centroids.

Differences in relative abundances by taxonomic ranks among all twelve treatment combinations were depicted in bar plots, and statements regarding significant differences are supported by tables in the Supplementary Materials. To generate the tables, the square root of the arc sine transformation was applied to percentage data and then, for each line in a table, the Fligner-Killen test was used to check for heterogeneity of variances $(\alpha=0.1)$. R's one-way test function was used as the global test for significant differences among means, allowing for unequal variances if appropriate. If significant, multiple comparisons were made by pairwise $t$ tests with Benjamini and Hochberg corrections for multiple comparisons and allowing for unequal variances as appropriate. Similar comparisons between groups of treatments (e.g., averaging over all genotypes) were made in the same manner for more than two groups, or by Welch's two-sample test for two groups. Differences were declared significant at $\alpha=0.05$ unless stated otherwise.

\section{RESULTS}

$16 S$ rRNA gene sequences. We obtained 2,925,909 16S rRNA partial gene sequences for the 47 samples retained in the study (one low P level root sample was lost). OTUs not classified by the RDP Classifier to the Kingdom Bacteria with a confidence of 0.5 were removed, leaving 2,893,048 counts in 30,134 OTUs, 165 of which were global singletons. Sequences per sample ranged from 14,472 to 129,166 with totals of $2,194,345$ and 698,703 in the rhizosphere and root samples, respectively. The number of bacterial sequences was much lower in the root compartment compared with rhizosphere because the primers used also amplify mitochondrial and plastid rRNA genes, which were removed during initial processing of sequences. Good's coverage (Good 1953) ranged from 92.6 to $97.7 \%$ with a mean of $95.7 \%$ and a standard deviation of 1.2.

ITS region sequences. We obtained $2,881,479$ ITS region sequences for the 47 samples. OTUs not classified by the RDP classifier to a fungal phylum with a confidence of 0.5 were removed, leaving 912,040 counts in 2,257 OTUs, eight of which were global singletons. Sequences per sample ranged from 3,456 to 68,841 , with totals of 616,448 and 295,592 in the soil and root samples, respectively. Good's coverage was high, ranging from 98.0 to $99.8 \%$ with a mean of $99.3 \%$ and a standard deviation of 0.3 .

Microbial community $\boldsymbol{\alpha}$-diversity. For bacteria in rhizosphere, variances were found heterogeneous for all measures of $\alpha$-diversity by the Fligner-Killeen test ( $\alpha=0.1$ ), and all had significant between treatment differences by one-way ANOVA allowing for unequal variances $(\alpha=0.05)$. Therefore, between treatment differences were found using all pairwise $t$ tests allowing for multiple comparisons, and the same lowercase letters in Table 1 indicate treatments not significantly different from each other $(\alpha=0.05)$. The Chao1 estimate of richness and Shannon diversity for communities on genotype L22 under the high P condition were lower than for any of the other treatments, which did not differ significantly from each other (Table 1). For the same samples, Pielou's $J$ index of evenness increased among communities on genotypes from L22 to L3 to the L3XL22 hybrid under the high $\mathrm{P}$ condition, but under the low $\mathrm{P}$ condition, evenness was equally high for all genotypes (Table 1).

For the fungi community in the rhizosphere, variances were not found heterogeneous for any measure of $\alpha$-diversity, and so comparisons in Table 1 were made by two-way ANOVA. For fungal richness in the rhizosphere, only genotype effects were significant, with the Chao1 estimate increasing from genotype L22 to L3 to the cross for both levels of $\mathrm{P}$, and only $\mathrm{P}$ level had a significant effect on Shannon and Pielou's $J$ indices with higher values under the high $\mathrm{P}$ condition (Table 1).

Without evidence for heterogeneity of variances, $\alpha$-diversity measures for both bacteria and fungi in roots were made by two-way ANOVA (Table 1). For bacterial richness in roots, both $\mathrm{P}$ level and genotype were significant $(P \leq 0.05)$, being higher under the high $\mathrm{P}$ condition and increasing from L22 to L3 to the hybrid. For fungal communities in the roots, however, only $\mathrm{P}$ level altered richness significantly $(P \leq 0.05)$. There were no significant $\mathrm{P}$ level or genotype effects for Shannon and Pielou's $J$ for bacteria or fungal communities in roots (Table 1).

Ordination. For bacterial $\beta$-diversity analysis, the first three PCoA axes explained more than $50 \%$ of the total variation in community structure (Fig. 1). PERMANOVA indicated that for the root samples, $\mathrm{P}$ level alone was significant to the ordination. For the rhizosphere samples however, there was a significant interaction between $\mathrm{P}$ level and genotype. The first two axes separate samples mainly by $\mathrm{P}$ level and plant compartments (root and rhizosphere). Additionally, for the rhizosphere samples at the high $\mathrm{P}$ level, the first two axes separate the communities on three genotypes and the third axis further separates genotype L22 from the others. Thus, there is a strong $\mathrm{P}$ and plant compartments effect on community structure, but under the high $\mathrm{P}$ condition, there is also a genotype effect.

Ordination using the ITS data were based on Bray-Curtis distances calculated from log-transformed counts, and the first two axes explained $45.5 \%$ of the total variation (Fig. 2). As with the $16 \mathrm{~S}$ rRNA data, dispersion did not differ significantly among treatment 
groups. PERMANOVA indicated both P level and compartmentation were significant to the ordination.

Taxonomic composition. Based on sequence counts, the prevalent bacterial phylum in most treatments was Proteobacteria (Fig. 3; Supplementary Table S1). The significant difference in the proportion of Proteobacteria between high and low $\mathrm{P}$ soil samples $(P=0.0002)$ was due mainly to the prevalence of $\gamma$-Proteobacteria $(32.2 \%)$ in the high $\mathrm{P}$ condition $\left(P=1.02 \mathrm{e}^{-06}\right)$, all genotypes pooled; most of these were Enterobacteriaceae (13.3\%), highest in the L22 samples (24.6\% of all counts), and Pseudomonadaceae (14.2\%) distributed among the three genotypes (counts vary from 9.8 to $19.4 \%$ among genotypes). Tenericutes was especially abundant in the high $\mathrm{P}$ root samples in which it accounted for $21.9 \%$ of all sequences, most of which were from 'Candidatus Phytoplasma' (class Mollicutes) found in the L22 samples $(41 \%)$. Considering low P, $\beta$-Proteobacteria (especially family Burkholderiaceae) and Chloroflexi phyla were predominant in the roots (27.4 and 6.1\%, respectively) and soil samples (25.7 and $5.6 \%$, respectively) (Fig. 4; Supplementary Table S2).

Ascomycota was by far the most prevalent fungal phylum in all treatments (Fig. 5; Supplementary Table S3). The significant differences at the class level include the higher abundance of Sordariomycetes (mainly Fusarium) in the high $\mathrm{P}$ rhizosphere comparing to roots ( 31.4 and $15.8 \%$, respectively, $P=4.6 \mathrm{e}^{-06}$ ) for all three genotypes Dothideomycetes were most abundant in the low $\mathrm{P}$ rhizosphere samples (51.4\%), and unclassified Pleosporales and Phoma account for much of this difference (Fig. 6; Supplementary Table S4).

The most notable difference among treatments was the prevalence of Glomeromycota with 34.5 and $3.6 \%$ of the total sequences in the low and high P root samples, respectively (Fig. 5). Nearly half of the sequences $(49.13 \%)$ were recovered from genotype L22 in roots, most of which were classified to the family Gigasporaceae, followed by Scutellosporaceae and Racocetraceae (Fig. 7; Supplementary Table S5).

\section{DISCUSSION}

$P$ soil fertilization affects the structure of microbial communities. While plant genotype has been shown to have a dramatic effect on root microbiome structure (Aira et al. 2010; Bonito et al. 2014; Picard and Bosco 2005; Picard et al. 2008; Tkacz et al. 2015), soil P levels may be a more significant driver for maize root microbiomes under nutrient limiting conditions in tropical oxisols. Our results show that the PCoA clearly separated the microbial groups based on $\mathrm{P}$ soil fertilization, followed by a secondary effect of plant compartmentalization in root and rhizosphere (Figs. 1 and 2; Supplementary File S1 provides statistical justification for ordination groups). These results are in line with previous studies where soil $\mathrm{P}$ availability was the main driver of bacterial and fungal communities (Silva et al. 2017; Tang et al. 2016). Yu et al. (2018) recently showed that soil P levels influenced the fungal community richness and species composition inside the roots in a manner specific for lateral and axial roots. We observed a substantial variation in bacterial and fungal $\alpha$-diversity both inside the roots and in the rhizosphere affected by the $\mathrm{P}$ level. Chao 1 estimates suggest a trend of increasing bacteria richness, whereas the opposite effect was observed on fungal communities on maize roots cultivated with high $P$. In contrast, high P reduced bacterial and increased fungal Shannon's diversity and Pielou's $J$ evenness in the rhizosphere (Table 1). Our results also show that root associated microbial communities had lower diversity indices than the rhizosphere communities. These results are consistent with previous studies showing that maize endophytic microbiota differ from those of the rhizosphere (Edwards et al. 2015; Miliute et al. 2015; Robbins et al. 2018). This probably occurred because the endophytic environment is more stable and uniform, and less affected by environmental changes (Miliute et al. 2015). However, a comparison between root and rhizosphere communities should be treated with caution because different DNA extraction kits were used for soil and roots.

TABLE 1

Diversity indices for bacterial and fungal communities in rhizosphere and $\operatorname{root}^{y}$

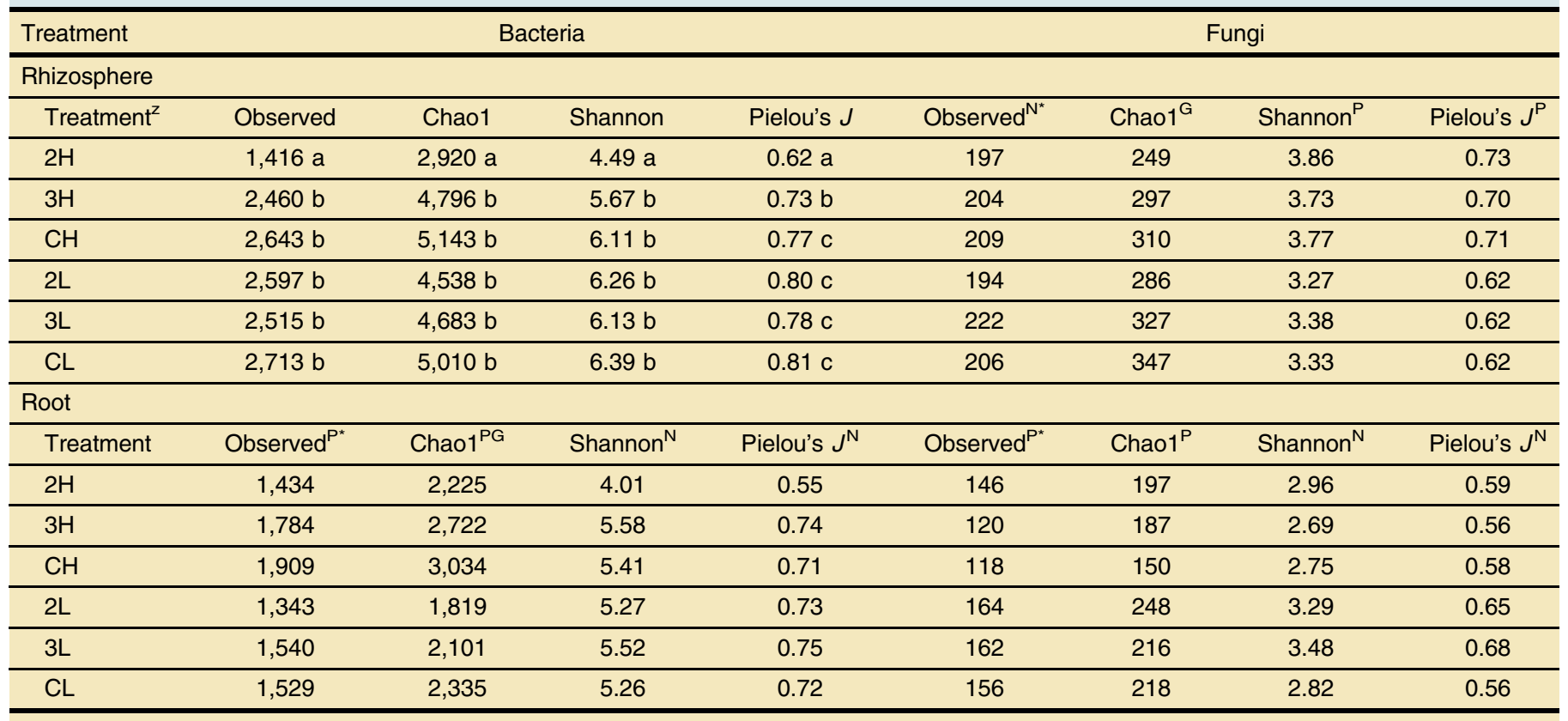

y Same letters in each column designate treatment groups that were not significantly different by pairwise $t$ tests without pooling standard deviations and with Benjamini and Hochberg correction for multiple comparisons $(\alpha=0.05) .{ }^{*}$ Indicates treatment effects were assessed by two-way analysis of variance; N, no significant differences among treatments; G, genotype effects were significant; and P, P effects were significant ( $\alpha=0.05)$.

z Treatment codes: 2 = genotype $L 22,3$ = genotype $L 3, C=$ genotype $L 22 x L 3 ; H$ high $P$ level, and $L=$ low $P$ level. 
We also observed a shift of bacterial taxa abundance according soil P status. Overall, Proteobacteria was the dominant phylum in all treatments (Fig. 3), as has been found in other studies with maize (Li et al. 2014; Peiffer et al. 2013; Silva et al. 2017). However, we observed a decrease in the ratio of Proteobacteria/Acidobacteria in the low $\mathrm{P}$ rhizosphere treatments, showing the positive effect of the $\mathrm{P}$ deficiency on Acidobacteria. This ratio has been suggested as an indicator of the trophic level of soils, with Proteobacteria favored in nutrient-rich conditions (Gottel et al. 2011). Numerous studies have reported that nutrient addition, as $\mathrm{P}$ and $\mathrm{N}$, may shift bacteria toward a more copiotrophic community (Peiffer et al. 2013; Tang et al. 2016; Wang et al. 2016). In a recent study, Trabelsi et al. (2017) also found an increase in copiotrophic bacteria at high P level whereas oligotrophic ones increased with rock phosphate application at low P levels.

In this context, lower-order taxonomic analysis also demonstrated that specific fast-growing members of Enterobacteriaceae and Pseudomonadaceae were enriched in the rhizosphere of
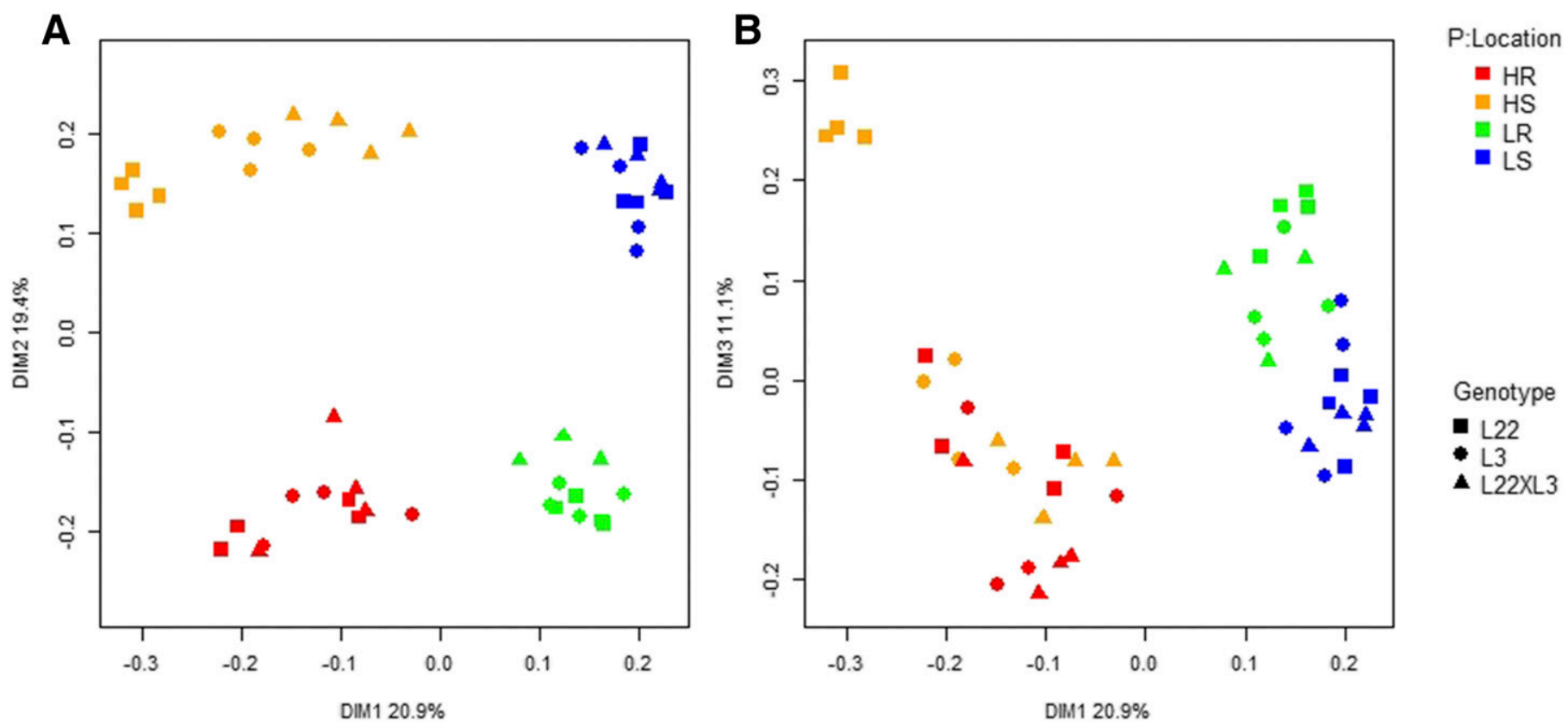

Fig. 1. Ordination of samples by principal coordinate analysis based on generalized UniFrac distances calculated from bacterial 16S rRNA gene sequence data. Samples separate by the four combinations of $P$ level and plant compartments. Rhizosphere samples under high $P$ conditions are further separated by genotype. H: high P level; L: low P level; R: roots; and S: soil (rhizosphere). Subfigures plot data by different dimensions, A, axes 1 versus 2 and $\mathbf{B}$, axes 1 versus 3 .
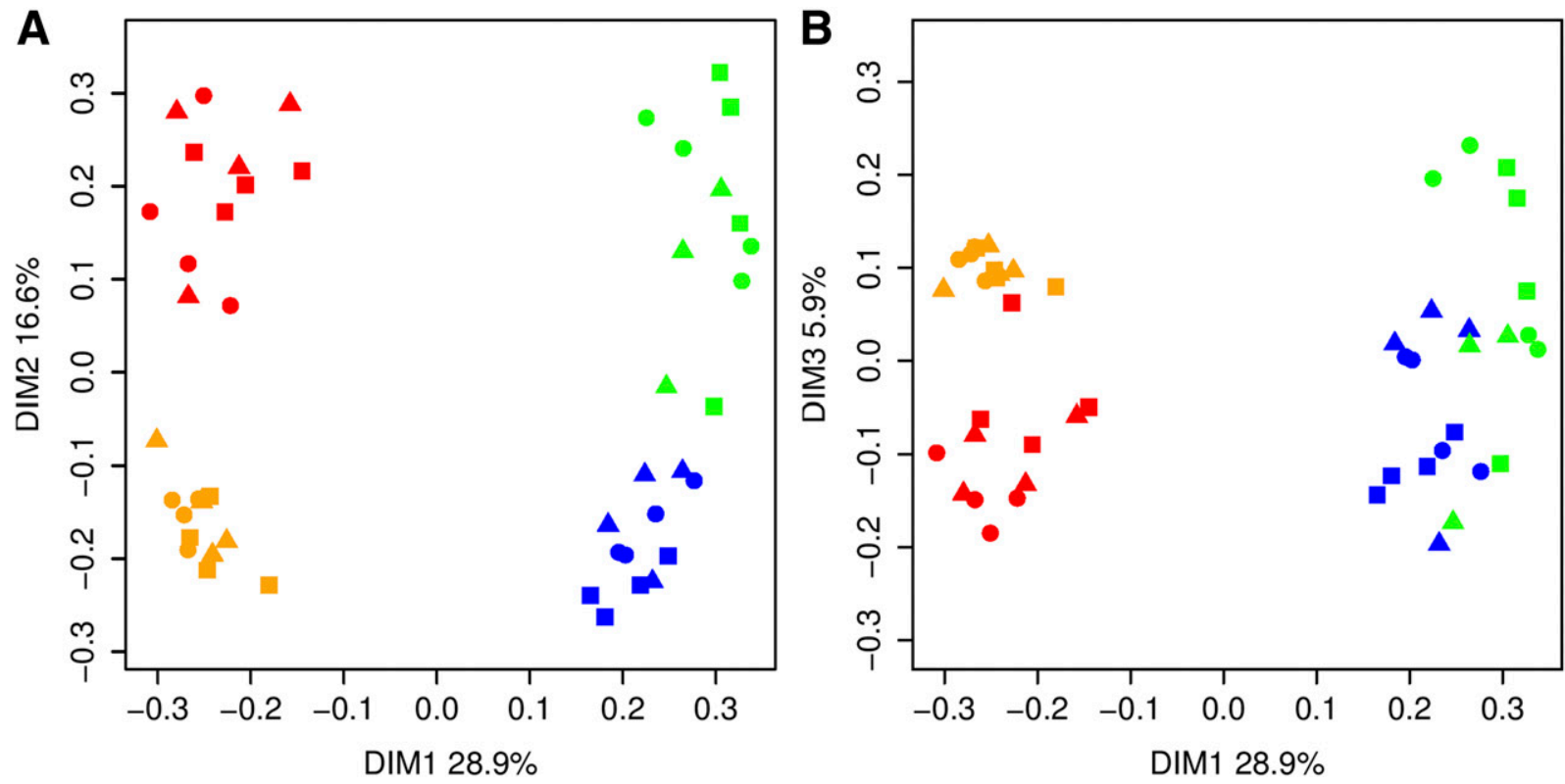

P:Location

- HR

- $\mathrm{HS}$

- $\mathrm{LR}$

- LS

Genotype

- L22

- L3

- L22XL3

Fig. 2. Ordination of samples by principal coordinate analysis based on Bray-Curtis distances calculated from log-transformed fungal ITS sequence data. Samples separate by the four combinations of $P$ level and plant compartment. Subfigures plot data by different dimensions, $\mathbf{A}$, axes 1 versus 2 and B, axes 1 versus 3. H: high P level; L: low P level; R: roots; and S: soil (rhizosphere). 
genotypes L22 and L3, respectively cultivated in high P soil (Fig. 4). Members of these families are typical of agroecosystems and well-known maize colonizers ( $\mathrm{Li}$ et al. 2014; Niu et al. 2017) as they utilize root metabolites, degrade aromatic compounds (Goldfarb et al. 2011), fix nitrogen and solubilize P (Oliveira et al. 2009a). They have high growth rates making them competitive for fresh organic material inputs from roots, and their presence in an ecosystem might indicate better soil fertility (Wakelin et al. 2012).

On the other hand, Burkholderiaceae was enriched in both root and rhizosphere of low P soils (Fig. 4). Members of this family are slow-growing oligotrophic bacteria and can survive in low carbon environments by being efficient in competition for resources and found in association with maize cultivated in tropical regions (Reis et al. 2004). They are plant growth promoting rhizobacteria, $P$ solubilizing, $\mathrm{N}_{2}$-fixing and catabolically versatile enabling them to degrade recalcitrant compounds and thus to survive in environments with limited nutrient availability.

The fungal community was dominated by Ascomycota (Fig. 5) which is consistent with previous studies of maize rhizosphere (Bokati et al. 2016). In our study, Ascomycota are likely both soilborne plant pathogens and saprophytes, probably because this experimental area is intensively cultivated with maize almost yearlong. This system can create conditions favorable for the proliferation and survival of these taxa, facilitating fungal dissemination during the plant development and over crop seasons.

Maize genotypes shape microbial communities in the root system. We knew that the maize genotypes used in this study differ in $\mathrm{P}$ use efficiency because under the low P conditions, L3 showed a significantly higher $\mathrm{P}$ acquisition efficiency (42\%) and grain yield (111\%) than L22 under field conditions (de Sousa et al. 2012; Parentoni et al. 2010). This may be explained at least in part by root architecture: under nutrient solution the efficient genotype L3 showed a higher shoot P content, root-shoot dry weight, root volume, and number of fine roots than L22 (de Sousa et al. 2012). This difference in fine roots is relevant, because of its interaction with the rhizosphere. Carbon from fine roots and root hair exudates

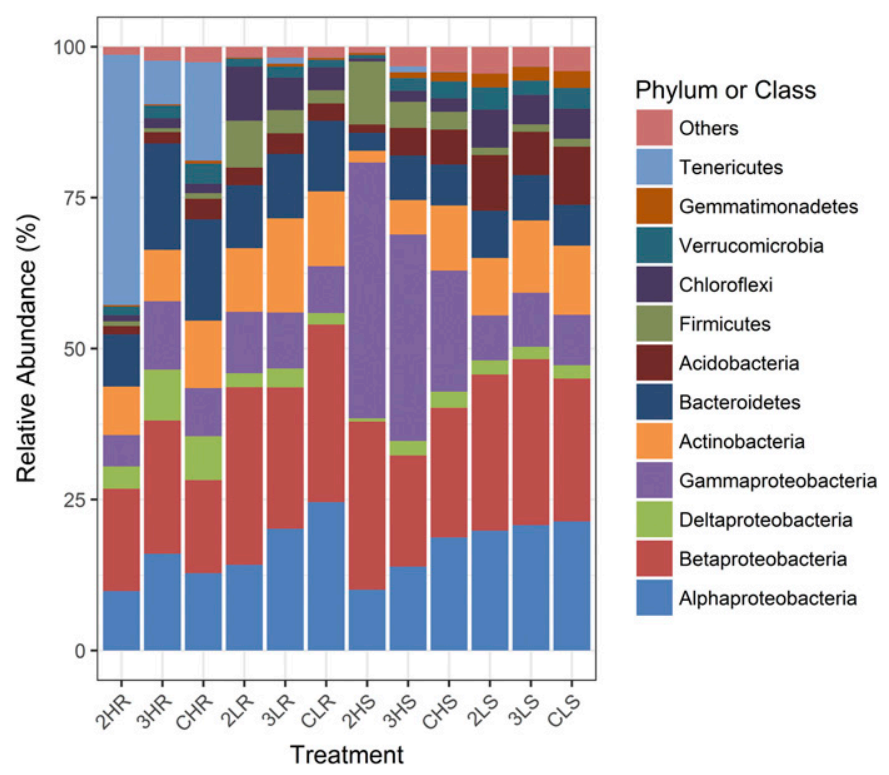

Fig. 3. Relative abundances (percentages of total 16S rRNA gene sequences) of bacterial phyla and Proteobacteria classes for all treatment combinations of $\mathrm{P}$ level, plant compartment, and genotype. Treatment codes: 2 = genotype $L 22,3$ = genotype $L 3, C=$ genotype $L 3 x L 22 ; H=$ high $\mathrm{P}$ level, $\mathrm{L}=$ low $\mathrm{P}$ level; $\mathrm{S}=$ soil samples, and $\mathrm{R}=$ root samples. stimulates microorganism activity and consequently changes soil short- and long-term community dynamics (Phillips et al. 2012; Schmidt et al. 2011; Tefs and Gleixner 2012).

Interestingly, in the present study under the high $\mathrm{P}$ treatment, bacterial communities on genotype L22 grouped separately from communities on L3 and the hybrid L3xL22, showing an effect of genotype on the bacterial $\beta$-diversity (Fig. 1). In addition, we observed a genotype effect on $\alpha$-diversity of bacteria in the roots and fungi in the rhizosphere communities, increasing from L22 to L3 to the hybrid (Table 1). The most direct explanation for the differences is the substantial influence plants exert over the rhizosphere microbiome through the quantity and/or quality of root exudates, that depend on external factors, physiological status, photosynthetic activity, and soil conditions, but is also species or even genotype specific (Picard and Bosco 2005; Semchenko et al. 2014; Walters et al. 2018). The contrasting P efficiency of L3 and L22 probably results in different exudates in the rhizosphere selecting specific groups of bacteria. In addition, as rhizodeposition of maize is affected by heterosis (Cavani and Mimmo 2007) the hybrid L3xL22 may have inherited from L3 the genetic traits that modify the chemistry of its rhizosphere, supporting a rhizobacterial population similar to L3 parent. From a QTL mapping for P acquisition efficiency, using recombinant inbred lines from the cross between L3 and L22, we know that both parents contribute with favorable alleles for P-acquisition efficiency traits in nutrient solution (Azevedo et al. 2015) and field (Mendes et al. 2014). Other authors also observed maize root colonization by auxin producers, e.g., Pseudomonas, an inherited trait regulated by heterosis (Picard and Bosco 2005). Although the effects of the genotype and fertilization are important separately, the complex interaction between these factors can further determine the rhizosphere microbial community structure. In this sense, the fertilization modifies the composition of root exudates leading to different microbial communities that may reciprocally alter the nutritional status of the plant (Tang et al. 2016).

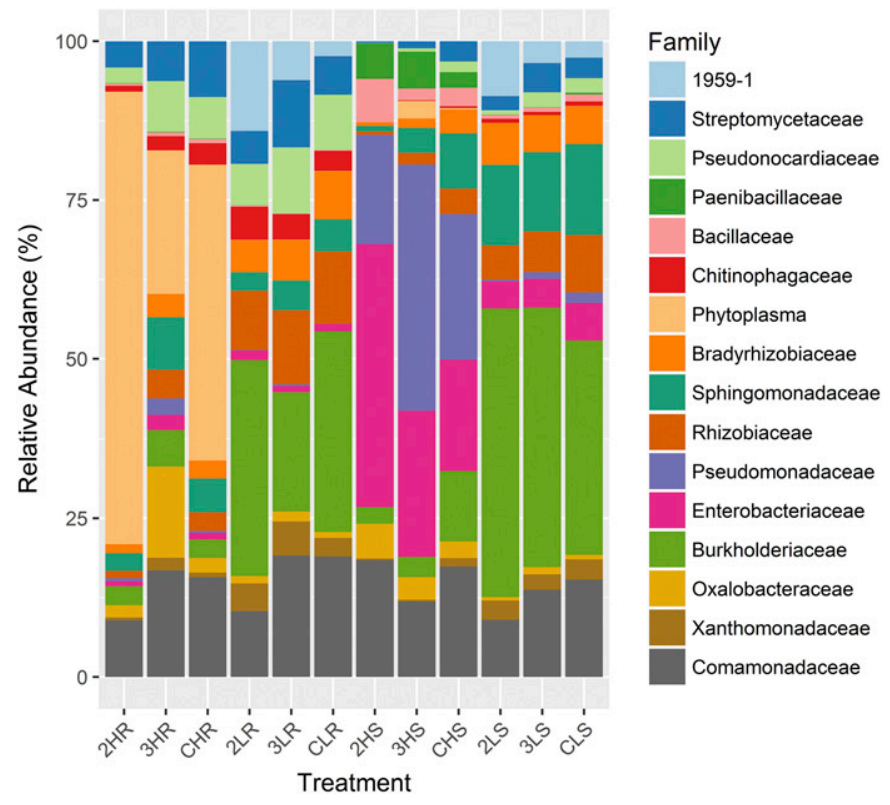

Fig. 4. Relative abundances of families in the top 15 bacterial OTUs in soil and roots (agglomerated to the 16 families they represent) for all treatment combinations of $\mathrm{P}$ level, plant compartment, and genotype. Treatment codes: 2 = genotype $L 22,3$ = genotype $L 3, C=$ genotype $L 3 x L 22 ; \mathrm{H}=$ high $\mathrm{P}$ level, $\mathrm{L}=$ low $\mathrm{P}$ level; $\mathrm{S}=$ soil samples, and $\mathrm{R}=$ root samples. 
$P$ availability drives the selection of AMF in the maize root system. Although AMF and PSB are involved in P cycling and they can be impacted by soil P status (Gosling et al. 2013; Mander et al. 2012; Trabelsi et al. 2017; Wakelin et al. 2012), we observed a positive effect of low $\mathrm{P}$ on AMF abundance, but our results did not support selection for microbes associated to plant growth promoting and $\mathrm{P}$ solubilization based on $\mathrm{P}$ availability.

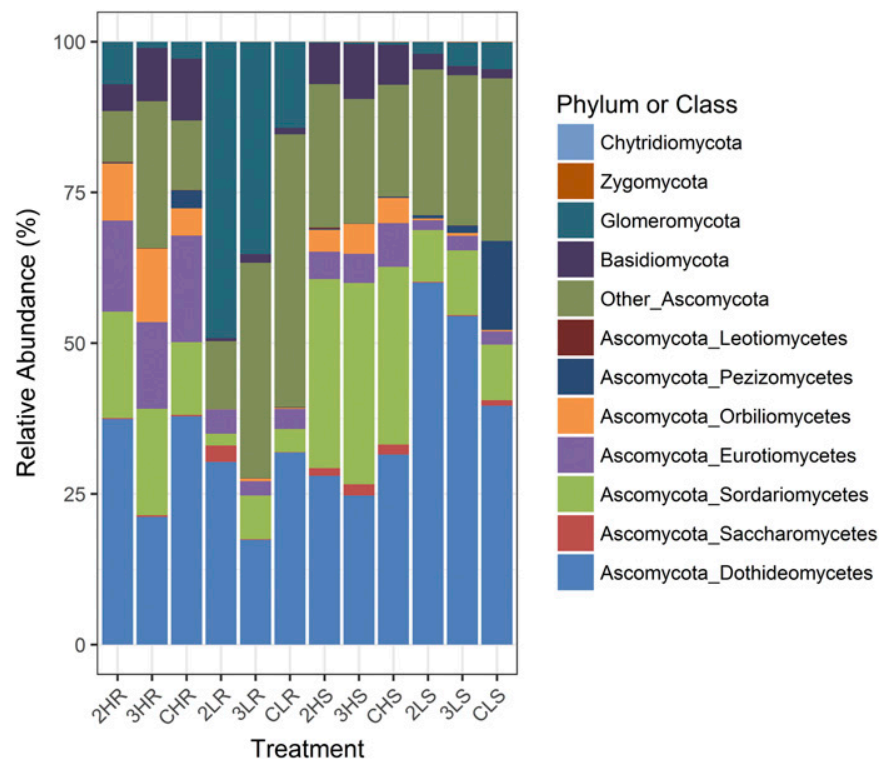

Fig. 5. Relative abundances (percentages of total ITS sequences) of fungal phyla and Ascomycota classes for all treatment combinations of $P$ level, plant compartment and genotype. Treatment codes: $2=$ genotype L22, 3 = genotype $L 3, C=$ genotype $L 3 x L 22 ; H=$ high $P$ level, $L=$ low $\mathrm{P}$ level; $\mathrm{S}=$ soil samples, and $\mathrm{R}=$ root samples.

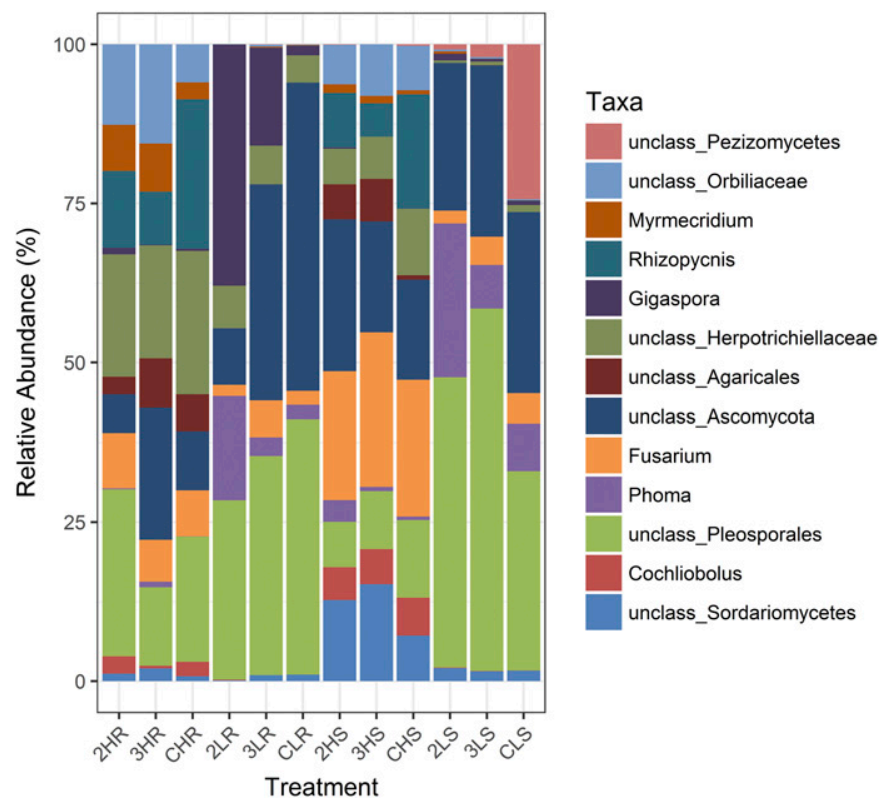

Fig. 6. Relative abundances of top 15 fungal OTUs in soil and roots (agglomerated to the 13 taxa they represent) for all treatment combinations of $\mathrm{P}$ level, plant compartment and genotype. Treatment codes: 2 = genotype L22, 3 = genotype L3, $\mathrm{C}$ = genotype L3xL22; $\mathrm{H}$ = high $P$ level, $L=$ low $P$ level; $S=$ soil samples, and $R=$ root samples.
The negative effect of $\mathrm{P}$ fertilization on AMF is well known (Gosling et al. 2013). Because plants can directly uptake nutrients from high P soil, they can reduce soluble carbohydrate supply for AMF, consequently reducing the colonization (Gosling et al. 2013). We observed that genotypes L22 and L3 presented respectively 49 and $35 \%$ of the total AMF colonization in the low $\mathrm{P}$ samples and Gigasporaceae was predominant in L22 and Racocetraceae in L3 genotype (Fig. 7). This corroborates and extends previous studies of our group showing the genus Racocetra abundant in roots of L3 in nonlimed soils (Gomes et al. 2015), suggesting its prevalence in abiotic stress conditions, such as Al toxicity and low $\mathrm{P}$ soil.

Several studies have reported an increased frequency of Psolubilizing bacterial phenotypes in low-P soils, demonstrating a selection for this trait based on P availability (Mander et al. 2012; Silva et al. 2017; Trabelsi et al. 2017). Although we have detected in the top bacterial OTUs such as Pseudomonas, Enterobacter, Azotobacter, Burkholderia, and Rhizobium (Fig. 4), frequently associated with plant growth promoting and phosphate solubilization abilities (Alori et al. 2017; Oliveira et al. 2009a; Wakelin et al. 2012), they were shared by different treatments and their presence was not related to $\mathrm{P}$ soil status. Based on this, we conclude that the effect of $\mathrm{P}$ fertilization was not reflected in the relative abundance of these taxa, indicating that $P$ fertilization did not stimulate specific groups of microorganisms, as PSB for example. These findings are in line with Browne et al. (2009) who did not see selection for strong P-solubilizing Pseudomonas fluorescens under reduced P inputs or Robbins et al. (2018) who did not observe a phylogenetic signature in the OTUs responding to altered soil P status. In this same context, Tang et al. (2016) concluded that $\mathrm{P}$ fertilization stimulated the overall bacterial and fungal community rather than a specific group of PSB and Fernández et al. (2015) did not observe an effect on PSB communities among sites containing extractable $\mathrm{P}$ levels ranging from 11.9 to $296.5 \mathrm{ppm}$.

Our results expand knowledge on the microbial community structures from different maize genotypes grown in soils with contrasting $\mathrm{P}$ availability and points to research directions in which matched plant genotype and inocula could be targeted for these highly weathered tropical soils to optimize plant productivity. Ultimate success will depend on the extent plant genotype can favor beneficial microbial communities in low P oxisols over time, sites, and probably growing conditions.

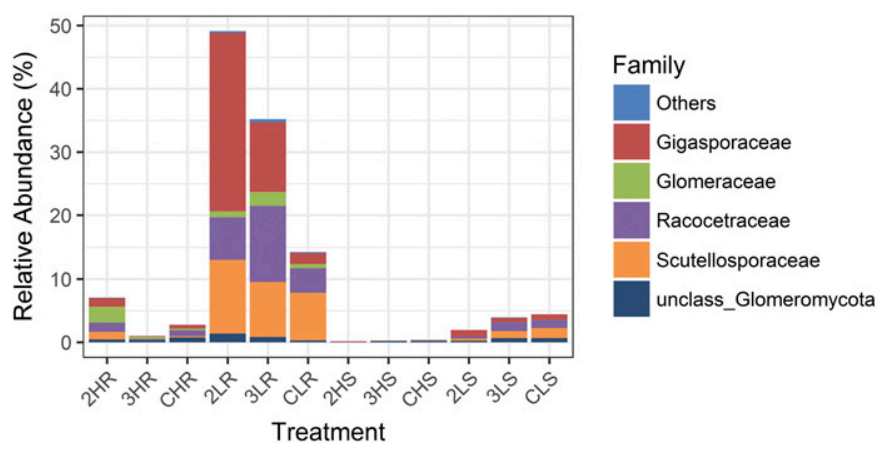

Fig. 7. Relative abundances of Glomeromycota families (percentages of total fungal sequences) for all treatment combinations of $P$ level, plant compartment, and genotype. Treatment codes: 2 = genotype L22, 3 = genotype L3, C = genotype L3xL22; H = high P level, L = low P level; $\mathrm{S}=$ soil samples, and $\mathrm{R}=$ root samples. 
LITERATURE CITED

Aira, M., Gómez-Brandón, M., Lazcano, C., Bååth, E., and Domínguez, J. 2010. Plant genotype strongly modifies the structure and growth of maize rhizosphere microbial communities. Soil Biol. Biochem. 42:2276-2281.

Alori, E. T., Glick, B. R., and Babaloa, O. O. 2017. Microbial phosphorus solubilization and its potential for use in sustainable agriculture. Front. Microbiol. 8:971.

Anderson, M. J. 2001. A new method for non-parametric multivariate analysis of variance. Austral Ecol. 26:32-46.

Aronesty, E. 2013. Comparison of sequencing utility programs. Open Bioinform. J. 7:1-8.

Azevedo, G. C., Cheavegatti-Gianotto, A., Negri, B. F., Hufnagel, B., Silva, L. C., Magalhães, J. V., Garcia, A. A. F., Lana, U. G. P., de Sousa, S. M., and Guimarães, C. T. 2015. Multiple interval QTL mapping and searching for PSTOL1 homologs associated with root morphology, biomass accumulation and phosphorus content in maize seedlings under low-P. BMC Plant Biol. 15:172.

Bakker, M. G., Chaparro, J. M., Manter, D. K., and Vivanco, J. M. 2015. Impacts of bulk soil microbial community structure on rhizosphere microbiomes of Zea mays. Plant Soil 392:115-126.

Bokati, D., Herrera, J., and Poudel, R. 2016. Soil influences colonization of root-associated fungal endophyte communities of maize, wheat, and their progenitors. J. Mycol. 8062073.

Bonito, G., Reynolds, H., Robeson, M. S., II, Nelson, J., Hodkinson, B. P., Tuskan, G., Schadt, C. W., and Vilgalys, R. 2014. Plant host and soil origin influence fungal and bacterial assemblages in the roots of woody plants. Mol. Ecol. 23:3356-3370.

Browne, P., Rice, O., Miller, S. H., Burke, J., Dowling, D. N., Morrissey, J. P., and O'Gara, F. 2009. Superior inorganic phosphate solubilization is linked to phylogeny within the Pseudomonas fluorescens complex. Appl. Soil Ecol. 43:131-138.

Caporaso, J. G., Kuczynski, J., Stombaugh, J., Bittinger, K., Bushman, F. D., Costello, E. K., Fierer, N., Peña, A. G., Goodrich, J. K., Gordon, J. I., Huttley, G. A., Kelley, S. T., Knights, D., Koenig, J. E., Ley, R. E., Lozupone, C. A., McDonald, D., Muegge, B. D., Pirrung, M., Reeder, J., Sevinsky, J. R., Turnbaugh, P. J., Walters, W. A., Widmann, J., Yatsunenko, T., Zaneveld, J., and Knight, R. 2010. QIIME allows analysis of high-throughput community sequencing data. Nat. Methods 7:335-336.

Caporaso, J. G., Lauber, C. L., Walters, W. A., Berg-Lyons, D., Lozupone, C. A., Turnbaugh, P. J., Fierer, N., and Knight, R. 2011. Global patterns of $16 \mathrm{~S}$ rRNA diversity at a depth of millions of sequences per sample. Proc. Natl. Acad. Sci. USA 108:4516-4522.

Cavani, L., and Mimmo, T. 2007. Rhizodeposition of Zea mays L. as affected by heterosis. Arch. Agron. Soil Sci. 53:593-604.

de Sousa, S. M., Clark, R. T., Mendes, F. F., de Oliveira, A. C., Vasconcelos, M. J. V., Parentoni, S. N., Kochian, L. V., Guimaraes, C. T., and Magalhães, J. V. 2012. A role for root morphology and related candidate genes in $P$ acquisition efficiency in maize. Funct. Plant Biol. 39:925-935.

Edwards, J., Johnson, C., Santos-Medellin, C., Lurie, E., Podishetty, N. K., Bhatnagar, S., Eisen, J. A., and Sundaresan, V. 2015. Structure, variation, and assembly of the root-associated microbiomes of rice. Proc. Natl. Acad. Sci. USA 112:E911-E920.

Egger, K. N. 1995. Molecular analysis of ectomycorrhizal fungal communities. Can. J. Bot. 73:1415-1422.

Fageria, N. K. 2009. The Use of Nutrients in Crop Plants. CRC Press, Boca Raton, FL.

Fernández, L. A., Agaras, B., Wall, L. G., and Valverde, C. 2015. Abundance and ribotypes of phosphate-solubilizing bacteria in Argentinean agricultural soils under no-till management. Ann. Microbiol. 65:1667-1678.

Goldfarb, K. C., Karaoz, U., Hanson, C. A., Santee, C. A., Bradford, M. A., Treseder, K. K., Wallenstein, M. D., and Brodie, E. L. 2011. Differential growth responses of soil bacterial taxa to carbon substrates of varying chemical recalcitrance. Front. Microbiol. 2:1-10.

Gomes, E. A., Oliveira, C. A., Lana, U. G. P., Noda, R. W., Marriel, I. E., and de Souza, F. A. 2015. Arbuscular mycorrhizal fungal communities in the roots of maize lines contrasting for Al tolerance grown in limed and non-limed Brazilian oxisol. J. Microbiol. Biotechnol. 25:978-987.

Good, I. J. 1953. The population frequencies of species and the estimation of population parameters. Biometrika 40:237-264.

Gosling, P., Mead, A., Proctor, M., Hammond, J. P., and Bending, G. D. 2013. Contrasting arbuscular mycorrhizal communities colonizing different host plants show a similar response to a soil phosphorus concentration gradient. New Phytol. 198:546-556.
Gottel, N. R., Castro, H. F., Kerley, M., Yang, Z. M., Pelletier, D. A., Podar, M., Karpinets, T., Uberbacher, E., Tuskan, G. A., Vilgalys, R., Doktycz, M. J., and Schadt, C. W. 2011. Distinct microbial communities within the endosphere and rhizosphere of Populus deltoides roots across contrasting soil types. Appl. Environ. Microbiol. 77:5934-5944.

Hoecker, N., Keller, B., Piepho, H. P., and Hochholdinger, F. 2006. Manifestation of heterosis during early maize (Zea mays L.) root development. Theor. Appl. Genet. 112:421-429.

Li, X. Z., Rui, J. P., Mao, Y. J., Yannarell, A., and Mackie, R. 2014. Dynamics of the bacterial community structure in the rhizosphere of a maize cultivar. Soil Biol. Biochem. 68:392-401.

Lynch, J. P. 2011. Root phenes for enhanced soil exploration and phosphorus acquisition: Tools for future crops. Plant Physiol. 156:1041-1049.

Magoč, T., and Salzberg, S. L. 2011. FLASH: Fast length adjustment of short reads to improve genome assemblies. Bioinformatics 27:2957-2963.

Mander, C., Wakelin, S., Young, S., Condron, L., and O'Callaghan, M. 2012. Incidence and diversity of phosphate-solubilising bacteria are linked to phosphorus status in grassland soils. Soil Biol. Biochem. 44:93-101.

Martin, M. 2011. Cutadapt removes adapter sequences from high-throughput sequencing reads. EMBnet J. 17:10-12.

Matsuo, T., and Hoshikawa, K. 1993. Morphology, Vol. 1. Science of the Rice Plant Morphology. Food and Agriculture Policy Research Center, Tokyo, Japan.

McMurdie, P. J., and Holmes, S. 2013. Phyloseq: An R package for reproducible interactive analysis and graphics of microbiome census data. PLoS One 8: e61217.

Mendes, F. F., Guimarães, L. J. M., Souza, J. C., Guimarães, P. E. O., Magalhaes, J. V., Garcia, A. A. F., Parentoni, S. N., and Guimaraes, C. T. 2014. Genetic architecture of phosphorus use efficiency in tropical maize cultivated in a low-p soil. Crop Sci. 54:1530-1538.

Miliute, I., Buzaite, O., Baniulis, D., and Stanys, V. 2015. Bacterial endophytes in agricultural crops and their role in stress tolerance: A review. Zemdirbyste 102:465-478.

Mota, D., Faria, F., Gomes, E. A., Marriel, I. E., Paiva, E., and Seldin, L. 2008. Bacterial and fungal communities in bulk soil and rhizospheres of aluminumtolerant and aluminum-sensitive maize Zea mays L. lines cultivated in unlimed and limed Cerrado soil. J. Microbiol. Biotechnol. 18:805-814

Niu, B., Paulson, J. N., Zheng, X., and Kolter, R. 2017. Simplified and representative bacterial community of maize roots. Proc. Natl. Acad. Sci. USA 114:E2450-E2459.

Novais, R. F., and Smyth, T. J. 1999. Fósforo em solo e planta em condições tropicais. Universidade Federal de Viçosa, Viçosa, MG.

Oehl, F., de Souza, F. A., and Sieverding, E. 2008. Revision of Scutellospora and description of five new genera and three new families in the arbuscular mycorrhiza-forming Glomeromycetes. Mycotaxon 106:311-360.

Oksanen, J., Blanchet, F. G., Friendly, M., Kindt, R., Legendre, P., McGlinn, D., Minchin, P. R., O'Hara, R. B., Simpson, G. L., Solymos, P., Stevens, M. H. H., Szoecs, E., and Wagner, H. 2017. Vegan: community ecology package. R package vegan, version 2.4-4. https:/cran.r-project.org/web/packages/ vegan/

Oliveira, C. A., Alves, V. M. C., Marriel, I. E., Gomes, E. A., Scotti, M. R., Carneiro, N. P., Guimarães, C. T., Schaffert, R. E., and Sá, N. M. H. 2009a. Phosphate solubilizing microorganisms isolated from rhizosphere of maize cultivated in an oxisol of the Brazilian Cerrado Biome. Soil Biol. Biochem. 41:1782-1787.

Oliveira, C. A., Sá, N. M. H., Gomes, E. A., Marriel, I. E., Scotti, M. R., Guimarães, C. T., Schaffert, R. E., and Alves, V. M. C. 2009b. Assessment of the mycorrhizal community in the rhizosphere of maize (Zea mays L.) genotypes contrasting for phosphorus efficiency in the acid savannas of Brazil using denaturing gradient gel electrophoresis (DGGE). Appl. Soil Ecol. 41: 249-258

Parentoni, S. N., de Souza, C. L., Alves, V. M. D., Gama, E. E. G., Coelho, A. M., de Oliveira, A. C., Guimarães, P. E. O., Guimarães, C. T., Vasconcelos, M. J. V., Pacheco, C. A. P., Meirelles, W. F., de Magalhães, J. V., Guimarães, L. J. M., da Silva, A. R., Mendes, F. F., and Schaffert, R. E. 2010. Inheritance and breeding strategies for phosphorus efficiency in tropical maize (Zea mays L.). Maydica 55:1-15.

Paschold, A., Marcon, C., Hoecker, N., and Hochholdinger, F. 2010. Molecular dissection of heterosis manifestation during early maize root development. Theor. Appl. Genet. 120:383-388.

Peiffer, J. A., Spor, A., Koren, O., Jin, Z., Tringe, S. G., Dangl, J. L., Buckler, E. S., and Ley, R. E. 2013. Diversity and heritability of the maize rhizosphere microbiome under field conditions. Proc. Natl. Acad. Sci. USA 110: 6548-6553. 
Phillips, R. P., Meier, I. C., Bernhardt, E. S., Grandy, A. S., Wickings, K., and Finzi, A. C. 2012. Roots and fungi accelerate carbon and nitrogen cycling in forests exposed to elevated $\mathrm{CO}_{2}$. Ecol. Lett. 15:1042-1049.

Picard, C., Baruffa, E., and Bosco, M. 2008. Enrichment and diversity of plantprobiotic microorganisms in the rhizosphere of hybrid maize during four growth cycles. Soil Biol. Biochem. 40:106-115.

Picard, C., and Bosco, M. 2005. Maize heterosis affects the structure and dynamics of indigenous rhizospheric auxins-producing Pseudomonas populations. FEMS Microbiol. Ecol. 53:349-357.

Reis, V. M., Estrada-de los Santos, P., Tenorio-Salgado, S., Vogel, J., Stoffels, M., Guyon, S., Mavingui, P., Baldani, V. L. D., Schmid, M., Baldani, J. I., Balandreau, J., Hartmann, A., and Caballero-Mellado, J. 2004. Burkholderia tropica sp. nov., a novel nitrogen-fixing, plant-associated bacterium. Int. J. Syst. Evol. Microbiol. 54:2155-2162.

Robbins, C., Thiergart, T., and Hacquard, S. 2018. Root-associated bacterial and fungal community profiles of Arabidopsis thaliana are robust across contrasting soil P levels. Phytobiomes J. 2:24-34.

Schmidt, M. W. I., Torn, M. S., Abiven, S., Dittmar, T., Guggenberger, G., Janssens, I. A., Kleber, M., Kögel-Knabner, I., Lehmann, J., and Manning, D. A. C. 2011. Persistence of soil organic matter as an ecosystem property. Nature 478:49-56.

Semchenko, M., Saar, S., and Lepik, A. 2014. Plant root exudates mediate neighbour recognition and trigger complex behavioural changes. New Phytol. 204:631-637.

Sharma, S. B., Sayyed, R. Z., Trivedi, M. H., and Gobi, T. A. 2013. Phosphate solubilizing microbes: sustainable approach for managing phosphorus deficiency in agricultural soils. Springerplus 2:587.

Silva, U. C., Medeiros, J. D., Leite, L. R., Morais, D. K., Cuadros-Orellana, S., Oliveira, C. A., Lana, U. G. P., Gomes, E. A., and dos Santos, V. L. 2017. Long-term rock phosphate fertilization impacts the microbial communities of maize rhizosphere. Front. Microbiol. 8:1266.

Smith, S. E., and Read, D. J. 2008. Mycorrhizal Symbiosis, 3rd ed. Elsevier Academic Press Inc, San Diego, CA.

Tang, X., Placella, S. A., Daydé, F., Bernard, L., Robin, A., Journet, E.-P., Justes, E., and Hinsinger, P. 2016. Phosphorus availability and microbial community in the rhizosphere of intercropped cereal and legume along a P-fertilizer gradient. Plant Soil 407:119-134.

Tefs, C., and Gleixner, G. 2012. Importance of root derived carbon for soil organic matter storage in a temperate old-growth beech forest-Evidence from $\mathrm{C}, \mathrm{N}$ and ${ }^{14} \mathrm{C}$ content. For. Ecol. Manage. 263:131-137.

Tkacz, A., Cheema, J., Chandra, G., Grant, A., and Poole, P. S. 2015. Stability and succession of the rhizosphere microbiota depends upon plant type and soil composition. ISME J. 9:2349-2359.

Trabelsi, D., Chernia, A., Zineba, A. B., Dhane, S. F., and Mhamdia, R. 2017. Fertilization of Phaseolus vulgaris with the Tunisian rock phosphate affects richness and structure of rhizosphere bacterial communities. Appl. Soil Ecol. 114:1-8.

Tremblay, J., Singh, K., Fern, A., Kirton, E. S., He, H., Woyke, T., Lee, J., Chen, F., Dangl, J. L., and Tringe, S. G. 2015. Primer and platform effects on 16S rRNA tag sequencing. Front. Microbiol. 6:771.

Wakelin, S., Mander, C., Gerard, E., Jansa, J., Erb, A., Young, S., Condron, L., and O'Callaghan, M. 2012. Response of soil microbial communities to contrasted histories of phosphorus fertilisation in pastures. Appl. Soil Ecol. 61:40-48.

Walters, W. A., Jin, Z., Youngblut, N., Wallace, J. G., Sutter, J., Zhang, W., González-Peña, A., Peiffer, J., Koren, O., Shi, Q., Knight, R., del Rio, T. G., Tringe, S. G., Buckler, E. S., Dangl, J. L., and Ley, R. E. 2018. Large-scale replicated field study of maize rhizosphere identifies heritable microbes. Proc. Natl. Acad. Sci. USA 115:7368-7373.

Wang, Y., Ji, H., and Gao, C. 2016. Differential responses of soil bacterial taxa to long-term P, N, and organic manure application. J. Soils Sediments 16: 1046-1058.

White, T. J., Bruns, T., Lee, S., and Taylor, J. 1991. Amplification and direct sequencing of fungal ribosomal RNA genes for phylogenetics. Pages 315-322 in: PCR Protocols: A Guide to Methods and Applications. Academic Press, Inc.

Yu, P., Wang, C., Baldauf, J. A., Tai, H., Gutjahr, C., Hochholdinger, F., and Li, C. 2018. Root type and soil phosphate determine the taxonomic landscape of colonizing fungi and the transcriptome of field-grown maize roots. New Phytol. 217:1240-1253. 